\title{
Vinte anos de avaliação da educação básica no Brasil": aprendizagens e desafios
}

Maria Inês de Matos Coelho**

\section{Resumo}

artigo analisa como a avaliação nacional da educação escolar básica insere-se historicamente na administração do sistema educacional brasileiro, de modo articulado à construção científica dos fatores de qualidade, eficiência, eqüidade e produtividade. Considera a trajetória ao longo de vinte anos que constituiu o Sistema de Avaliação da Educação Básica - Saeb, estabelecido desde a segunda metade dos anos 90. Usando as revisões bibliográficas e os estudos do estado da arte na área temática, a pesquisa analisa os enfoques e aperfeiçoamentos do Saeb. Argumentamos que essa política de avaliação foi desenvolvida como uma parte de uma nova política de regulação e de administração competitiva no contexto do Estado Avaliador. Finalmente, propomos questões para a reflexão sobre condições ou possibilidades de mudança.

Palavras-chave: Avaliação de Sistemas de Ensino. Políticas públicas e avaliação da Educação Básica. Estado-avaliador e Educação.

\section{Twenty years of the evaluation of the basic education in Brazil: learnings and challenges Abstract}

This article analyzes how the national evaluation of the basic school education has been historically inserted in the administration of the Brazilian educational system, together with the scientific construction of factors like quality, efficiency, equity and productivity. It considers the trajectory along twenty years which has built the SaebEvaluation System of the Basic Education established since the late nineties. Using the bibliographical reviews and the state of the art studies in this area, the research analyzes Saeb's focus and improvements. We argued that this evaluation politics has been developed as part of the new regulation and competitive administration politics in the context of the Evaluator State. Finally, we suggest topics as the reflection on conditions and change possibilities.

Keywords: Evaluation of Educational Systems. Public Politics and Basic Educational Evaluation. Evaluator State and Education.

\footnotetext{
Este texto resulta de trabalho realizado com apoio do CNPq (2001-2004) e da FAPEMIG, a partir de 2007.

" Doutora em Educação, Universidade Federal do Rio de Janeiro; Professora Emérita/Coordenadora do Mestrado em Educação, Universidade do Estado de Minas Gerais.

E-mail: teiaweb@uai.com.br
} 


\section{Veinte años de la evaluación de la educación básica en Brasil: aprendizajes y desafíos Resumen}

El artículo analiza cómo la evaluación nacional de la educación escolar básica se ha insertado históricamente en la administración del sistema educativo brasileño, de una manera articulada con la construcción científica de los factores de la cualidad, eficiencia, equidad y productividad. Considera la trayectoria a lo largo de veinte años que han constituido lo Saeb - el Sistema de la Evaluación de la Educación Básica establecido desde la segunda mitad de los años 90. Usando las revisiones bibliográficas y los estudios del estado del arte en el área temática, la investigación analiza los enfoques y mejoras del Saeb. Nosotros defendimos que la política de la evaluación se desarrolló como una parte de una nueva política de la regulación y de una administración competitiva en el contexto del Estado-Evaluador. Finalmente, proponemos temas para la reflexión sobre condiciones o posibilidades de cambio.

Palabras clave: Evaluación de los Sistemas Educativos. Políticas públicas y evaluación de la Educación Básica. Estado-evaluador y Educación.

\section{Introdução}

A discussão dos problemas da educação básica no Brasil tem sido marcada, nos últimos anos, pela divulgação mais ampla de informações produzidas pelo sistema de avaliação externa, em larga escala, centralizada e com foco no rendimento do aluno e no desempenho dos sistemas de ensino. As avaliações dos desempenhos de aprendizagem em Lingua Portuguesa e em Matemática dos estudantes do sistema público de educação básica, nos segmentos do ensino fundamental e do ensino médio, e seus resultados insatisfatórios ao longo de mais de dez anos, alimentam polêmicas em diferentes espaços e, sobretudo na mídia, acerca das políticas públicas e da gestão educacional. Essa situação assume contornos diferentes quando compreendemos como a avaliação se inseriu historicamente na gestão do sistema educacional brasileiro.

É preciso lembrar conforme informação que nos traz Azevedo (2000) que, no âmbito do Estado brasileiro, o interesse pela avaliação sistêmica na organização do setor educacional já se manifestava nos anos 30. Por outro lado, Waisenfisz (1991) esclarece que foi nos esboços de pesquisa e de planejamento educacional desenvolvidos desde então, que se deram as bases para a elaboração de uma proposta de um sistema nacional de avaliação, ao final dos anos 80. Mas, foi nos meados dos anos 90 que a avaliação da educação básica foi implantada e se foi consolidando pela avaliação externa da escola pelo Saeb - Sistema de Avaliação da Educação Básica, com base em resultados da aprendizagem aferidos por recursos quantitativos.

Desde meados dos anos 90, o Saeb foi implantado e tem-se consolidado no campo das políticas públicas com o "principal objetivo de contribuir para a melhoria da qualidade da educação brasileira e para a universalização do acesso à escola, oferecendo subsídios concretos para a formulação, reformulação e o monitoramento das políticas públicas voltadas para a educação básica" (BRASIL, 2002, p. 9). 
Atualmente, esse sistema, além do exame por amostragem (Saeb), conta ainda com a Prova Brasil introduzida em 2005, para avaliar o desempenho em Lingua Portuguesa e em Matemática em cada unidade escolar, e o Índice de Desenvolvimento da Educação Básica - Ideb, criado em 2007, para monitorar o andamento das políticas públicas pela análise combinada do desempenho dos alunos nos exames Prova Brasil e Saeb e das taxas de aprovação de cada escola.

O discurso oficial enfatiza a crise de ineficácia do sistema educacional brasileiro, no bojo da qual está o desempenho das escolas e dos professores, de um lado, como fator de resultados insatisfatórios de aprendizagem dos alunos tais como os aferidos pelo Saeb. De outro lado, este desempenho é dimensão de qualidade a ser ativada pela formação profissional e por mecanismos de avaliação e incentivo por mérito, aspectos sendo estimulados e implantados na nova versão do Saeb - a Prova Brasil.

Compreendemos que, é no conjunto de ações implementadas no contexto da reestruturação do Estado brasileiro, que esse discurso oficial se insere e, como tal, conduz a novos marcos regulatórios no sentido de manejar a construção da identidade dos profissionais da educação, principalmente dos professores, enfatizando a participação e as condições de trabalho desses profissionais para melhor arquitetar ou reestruturar a educação básica. Esse discurso da política pública brasileira dos últimos vinte anos relaciona-se com recomendações de organismos internacionais que insistem nas ações para superar a crise de eficiência, eficácia e produtividade do sistema. Tal discurso aponta como principal problema a ser sanado o desencontro entre o sistema educacional e as necessidades do mercado de trabalho. A saída da crise, segundo essa orientação política, está em tratar a educação e o conhecimento como eixos da transformação produtiva com equidade, e como fator de competitividade das nações e das empresas (CEPAL; UNESCO, 1995). Em relação a essa concepção, é necessário considerar criticamente que a educação pode estar sendo transformada em uma mera possibilidade de consumo individual, variando segundo o mérito e a capacidade dos consumidores, o que pode acabar por lhe negar a condição de direito social.

A avaliação se firma cada vez mais como elemento da regulação e da administração gerencial e competitiva do "Estado-avaliador"l no Brasil, com uma história de mais de vinte anos. Há, portanto, necessidade e relevância de uma reflexão sobre a relação entre a centralidade que a avaliação da educação básica tem recebido na política pública e as tendências na construção científica de seus processos e resultados bem como sobre suas implicações na gestão escolar e no trabalho dos profissionais da escola.

Este artigo apresenta e discute resultados de pesquisa realizada sobre as tendências na avaliação da educação básica, nos últimos vinte anos no Brasil, tendo como caminho metodológico a identificação e análise de trabalhos considerados como

\footnotetext{
' Considera-se a concepção de Estado-avaliador desenvolvida pelos estudos de Guy Neave $(1988,1998)$ no âmbito de trabalhos relativos às políticas de ensino superior e por Afonso (2001) ao relacioná-lo com a

"radicalização" da "figura do Estado intervencionista", ou seja, aumento de interferência e controle pelo Estado por meio da avaliação sistêmica.
} 
marcos de tendências em revisões bibliográficas e estudos do estado da arte na área temática. Também foram analisados relatórios divulgados pelo INEP-MEC e estudos realizados com base no Saeb.

Explicitando os movimentos da avaliação da educação básica no Brasil, abordamos em primeiro lugar como se inicia a avaliação sistêmica da educação básica no âmbito do Estado brasileiro. Depois, focalizamos como se consolida a avaliação sistêmica da educação básica no âmbito do Estado brasileiro e, particularmente, como se desenvolve, pela pesquisa, a busca da "escola eficaz". $\bigcirc$ texto discute, em seguida, como a construção científica da avaliação orienta deslocamento de focos e aperfeiçoamentos no sistema Saeb, encerrando-se com reflexões sobre o "Estado-avaliador" e suas políticas de regulação e de administração gerencial na educação básica no Brasil.

\section{Os primeiros movimentos da avaliação sistêmica da educação básica no âmbito do Estado brasileiro}

Na gestão pública da educação brasileira, a proposta inicial de um sistema nacional de avaliação ocorre no final dos anos 80 , embora fosse objeto de interesse já na reforma dos anos 30 e estivesse presente, desde então, nos esboços de pesquisa e de planejamento educacional (AZEVEDO, 2000; WAISENFISZ, 1991).

As perspectivas economicista e tecnicista no tratamento da questão da avaliação educacional, ao lado do questionamento acadêmico e social da qualidade do ensino e da reivindicação de descentralização, concorreram para que, no início dos anos 80, fossem iniciadas, pelo Estado, as experiências de avaliação em larga escala e, ao final da década, fosse implantado um sistema nacional de avaliação, com vistas à modernização do setor educacional. Esse sistema foi gestado por esforços, cujas principais razões foram apontadas em síntese de estudo sobre a avaliação nesse período (FREITAS, 2005, p. 7):

Os motivos (declarados) para que o Estado buscasse "medir, avaliar e informar" foram diversos no percurso 1930-1988. Primeiro, essas práticas foram tidas como necessárias porque se prestariam a conferir e verificar resultados frente a objetivos da educação nacional, proporcionando a aplicação da ciência para "formar a consciência técnica" no âmbito escolar, posto que condição necessária à expansão e à melhoria da educação. A seguir, tais práticas propiciariam ao Estado central "conhecer a realidade" e fazer "diagnósticos" com o que, em lugar de acentuar-se a regulação pela via legal, seriam fornecidas "indicações e sugestões" para a qualificação da expansão do atendimento, da administração escolar e do ensino. No momento seguinte, "medir, avaliar e informar" foram práticas consideradas importantes para a instrumentação da racionalização, da modernização e da tutela da ação educacional. Logo a seguir, os motivos para recorrer a essas práticas se reportaram às tarefas de reajustar a regulação estatal e de criar uma cultura de avaliação no País. 
Esse primeiro movimento da avaliação da educação básica no Brasil se relaciona também com o que ocorre e impulsiona a avaliação educacional no contexto internacional. Constituem parte desse contexto de influência, a aprovação do Primary and Secondary Education Act, em 1965, nos Estados Unidos e a publicação do Informe Coleman em 1968, que se conjugam com a criação da Internacional Association for the Evaluation of Educacional Achievement - IEA, que se propõe a promover e realizar estudos internacionais de avaliação educacional, e ainda com a experiência de construção, nos anos de 1970, de indicadores internacionais de qualidade da educação pela Organização para a Cooperação e Desenvolvimento Econômico - OCDE.

Marcos na investigação acerca de desigualdades sociais e educacionais, as pesquisas de Coleman e outros (1966) e de Jencks e outros (1972) analisaram a "função de produção da escola" (modelo de input-output), aplicando análise de regressão a amostras de estudantes da escola elementar e secundária e avaliando se os recursos humanos, materiais e financeiros (despesas por aluno) e as características dos alunos (as entradas) estavam associados aos resultados escolares dos alunos (a saída). Esses estudos enfraqueceram substancialmente a esperança liberal de que o acesso à escolarização pode criar igualdade de oportunidades. A eles se juntaram, em 1967, o Relatório Plowden na Grã Bretanha e os estudos internacionais do IEA. A despeito das polêmicas em torno de aspectos metodológicos dessas pesquisas, a conclusão é a de que as escolas não se mostravam efetivas, como se supunha, para eliminar deficit de aprendizagem que derivavam de desigualdades econômicas, sociais e culturais nas famílias dos estudantes. Na análise sociológica, esses resultados fundamentavam o ceticismo quanto ao papel da escola. Convergiam com as teorias de reprodução social e cultural de que a educação escolar na sociedade capitalista não apenas conserva como até reforça e legitima a estrutura social existente.

No Brasil, de 1987 a 1990, o Ministério da Educação investiu no desenvolvimento do Sistema de Avaliação do Ensino Público de $1^{\circ}$ Grau - Saep. Como salienta Sousa (1997), enquanto as pesquisas apontavam para as implicações educacionais e sociais da avaliação, o poder público recorria à testagem do rendimento do aluno, sendo este tomado como expressão do desempenho de escolas e sistemas. No mesmo período, a ampla difusão e discussão das teorias da reprodução cultural e social colocavam a descoberto a função seletiva e excludente da educação brasileira. A reflexão crítica marcava os debates na elaboração do novo texto constitucional.

Na Constituição Federal de 1988 (BRASIL, 1988), avaliação educacional é tratada de forma associada à qualidade da educação. No art. 206, a "garantia de padrão de qualidade" figura como um dos princípios basilares do ensino. No art. 209, a avaliação da qualidade pelo poder público aparece como condição do ensino livre à iniciativa privada. Ao tratar do Plano Nacional de Educação, o art. 214 indica como um dos resultados pretendidos a "melhoria da qualidade do ensino" (BRASIL, 1988). 
Do ponto de vista de análise do Estado, em momento de crise, a avaliação foi, então, vista como uma estratégia útil para a gestão.

A introdução da avaliação em larga escala na regulação da educação básica se deu no contexto de crise do Estado desenvolvimentista, num quadro de busca de recomposição do poder político, simbólico e operacional de regulação pelo Estado central e de restrições à sua atuação na área social, ligando-se ao movimento reformista que, no ingresso dos anos 1990, impôs uma nova agenda para a área social. Essa agenda apontou para uma reorganização profunda dos princípios e parâmetros de estruturação das políticas sociais, remetendo à questão da reforma do Estado e dos caminhos da modernização do País (NEPP, 1991). A avaliação foi, então, vista como uma estratégia útil para a gestão que se impunha com o rumo que vinha sendo dado à área social (FREITAS, 2005, p. 9).

No campo da pesquisa, estavam sendo reunidas evidências sobre os fatores escolares a serem considerados nas políticas públicas e na gestão educacional. $\bigcirc$ estudo de Madaus e outros (1980, p. 103-105) explicitou o "efeito diferencial" que as escolas exercem sobre o desempenho de estudantes mais por fatores processuais relacionados ao clima escolar e concluiu sobre a contribuição relevante de "qualidade do ensino" definida em termos de processos de sala de aula.

Já na pesquisa de Bloom (1981), a hipótese de diferenças individuais de aprendizagem, explicada por condições da família e da escola, se contrapõe à idéia de diferenças individuais nos alunos. $\bigcirc$ autor propõe que a escola pode aproximar-se de um sistema "isento de erros" pela consideração de três grupos de variáveis: os pré-requisitos básicos do aluno para a aprendizagem, a motivação do aluno para engajar-se no processo de aprendizagem e o ensino adequado ao aluno ${ }^{2}$. Portanto, a "qualidade de ensino" pode ser modificada em termos de tarefas de aprendizagem e relaciona-se com os incentivos ou diretrizes oferecidos ao aprendiz, com a sua participação na atividade de aprendizagem e com o reforço que se obtém em relação ao processo, abrangendo feedback e correção ${ }^{3}$.

Uma outra abordagem do impacto da escolarização sobre estudantes, ainda no final dos anos 70, já focalizava as características sociais e organizacionais de escolas "que fazem diferença". Conhecida como "pesquisa de escolas efetivas", essa abordagem se fez mais presente em estudos que identificaram características comuns às escolas nas quais os estudantes apresentavam desempenho superior ao que era esperado com base em suas características individuais de nível socioeconômico desfavorecido e de minorias culturais (BROOKOVER,1978; EDMONDS, 1979; BICKEL, 1983). Segundo Brookover (1978), o modelo de análise de "escolas efetivas" focaliza "entrada-processo-saída" e procura esclarecer os processos internos das escolas que determinam a sua eficácia, ou seja, a sua capacidade de interferir positivamente, através de políticas e práticas escolares, no desempenho dos alunos.

\footnotetext{
${ }^{2}$ BLOOM, B. S. Características humanas e aprendizagem escolar. Porto Alegre: Globo, 1981, p. 11.

${ }^{3}$ lbid., p. 114.
} 
Características de "efetividade da escola" foram reunidas em cinco elementos com base em estudos analisados por Bickel (1983, p. 4) e assim a "escola efeti$v a$ " ficou relacionada aos fatores: forte liderança instrucional (qualidades de liderança do diretor), clima escolar ordenado, altas expectativas em relação ao aluno, ênfase nas habilidades básicas e controle freqüente do progresso instrucional. Embora, esse conjunto de dimensões tenha sido mais divulgado, há uma estrutura conceitual com quatorze variáveis que, segundo Murphy e outros (1982), captam o que se conhece sobre escolas urbanas efetivas, em termos de conteúdos e normas organizacionais, estruturas necessárias para implementá-las e processos que facilitam sua concretização.

A proposta da "escola efetiva" começa a ser conhecida e analisada no Brasil em meados dos anos 80. Estudo apresentado por Coelho (1984) situa na formulação dessa concepção as tendências e resultados da pesquisa educacional acumuladas nos anos 60 e 70. Discute que a ênfase colocada sobre as variáveis tecnológicas da escola restringiu a efetividade da escola a um espaço instrucional e a cultura ficou reduzida a padrões de excelência escolar ("um currículo consistente" e "oportunidade para aprender"). Nessa efetividade, não são considerados os processos culturais específicos e de classe social que atuam na educação e na escolarização e que vinham sendo objeto de estudo pelo que era denominado de "nova sociologia da educação" e que se ligava à vertente de pesquisas de Michel Young, em continuidade crítica a Basil Bernstein, nos anos 70/80, como é bem esclarecido por Forquin (1993).

Nos anos 90, os estudos de efetividade da escola (School Effectiveness Research - SRE) ou da "escola eficaz" consolidam-se como um campo de pesquisa que visa a compreender, em cada contexto social, os processos internos das escolas que determinam a sua eficácia, ou seja, a sua capacidade de interferir positivamente, através de políticas e práticas escolares, no desempenho dos alunos (SAMMONS; HILLMAN; MORTIMORE, 1995). No Brasil, o trabalho "Escolas eficazes: um tema revisitado", de Mello (1994) situa o modelo como proposta de análise de tendências e de ação face aos desafios da gestão escolar.

Ainda nessa década, destaca-se a atuação de organismos internacionais como Organização das Nações Unidas para a Educação, a Ciência e a Cultura UNESCO, e Banco Mundial sendo impulsionadores externos das reformas educacionais. Um grande projeto de educação em nível mundial, com financiamento pelas agências UNESCO, Fundo das Nações Unidas para a Infância - UNICEF, Programa das Nações Unidas para o Desenvolvimento - PNUD e Banco Mundial e tendo como principal eixo a idéia da "satisfação das necessidades básicas de aprendizagem", foi lançado, para a década que se iniciava, na "Conferência Mundial sobre Educação para Todos" realizada em Jomtien, Tailândia, em março de 1990. Outro marco é o Relatório Delors (DELORS, 1998), produzido entre 1993 e 1996 pela Comissão Internacional sobre Educação para o Século XXI, convocada pela UNESCO, coordenada pelo francês Jacques Delors. Nele se fez um diagnóstico do "contexto planetário de interdependência e globalização" evidenciando-se desafios para cujo enfrentamento a educação seria o instrumento 
fundamental. ${ }^{4}$ Esses são alguns elementos que constituem bases na formulação e aprovação da Lei de Diretrizes e Bases da Educação Nacional - LDBEN (BRASIL, 1996), para a consolidação do sistema nacional de avaliação da educação básica no país.

\section{Como se consolida a avaliação sistêmica da educação básica no âmbito do Estado brasileiro: a busca da "escola eficaz"}

No decorrer dos anos de 1990, acentuadamente no período posterior a 1994, a sociedade brasileira viu ganhar centralidade o tema da qualidade do ensino como objeto de regulação federal, cuja viabilidade exigira o aporte de um sistema de informações educacionais conjugado a um sistema nacional de avaliação. Ambos são considerados elementos estratégicos da "boa-governança educacional" no país entendida como exercício dinâmico do ato de governar que implica capacidade de coordenação, de liderança, de implementação e de produção de credibilidade (COSTA, 1997).

O Saeb, a partir de 1990, substituiu o Sistema de Avaliação do Ensino Público de $1^{\circ}$ Grau - Saep, criado em 1987. A implantação do Saeb, com assistência internacional do PNUD 5 , ocorreu com a primeira aplicação de provas e o levantamento de dados em nível nacional, em 1990. A segunda aplicação do Saeb em 1993 foi estruturada em três eixos de estudo: (1) rendimento do aluno; (2) perfil e prática docentes; (3) perfil dos diretores e formas de gestão escolar. A partir de 1995, o Saeb incluiu em sua amostra o ensino médio e a rede particular de ensino; adotou técnicas mais modernas de medição do desempenho dos alunos; incorporou instrumentos de levantamento de dados sobre as características socioeconômicas e culturais e sobre os hábitos de estudo dos alunos; e redefiniu as séries avaliadas, $4^{a}$ e $8^{a}$ séries do ensino fundamental e $3^{a}$ série do ensino médio (BRASIL, 2001, p. 11). Nesse período, também ocorreu a reestruturação e modernização do sistema de estatísticas e indicadores educacionais e a ampliação dos meios operacionais de centralização da avaliação educacional com a inclusão de exames nacionais: o Exame Nacional do Ensino Médio - Enem - e o Exame Nacional de Certificação de Competências de Jovens e Adultos - Encceja. A ação avaliativa também se estendeu aos programas governamentais como: o Programa Nacional do

\footnotetext{
4 O compromisso de "Educação Básica para Todos" assumido em 1990 foi avaliado pelo Fórum Mundial de Educação de Dacar, promovido pela UNESCO, UNICEF, PNUD e Banco Mundial, em 2000, quando foram estabelecidas metas para superar as dificuldades identificadas na década de forma a atingir a "universalização da educação básica de qualidade".

${ }^{5}$ O projeto BRA/86/002 - Treinamento Gerencial para Projetos de Educação Básica (BRASIL, 1997), com fundos de projeto de empréstimo com o Banco Mundial, apoiou o desenvolvimento e a implantação do Saeb. Esse tipo de assistência do PNUD à melhoria do sistema de informações educacionais remonta ao final da década de 80. Com fundos do projeto BRA 86/002 foi planejada e implementada, em 1990, a primeira pesquisa nacional de avaliação do desempenho de alunos. O projeto, além de apoiar o desenvolvimento metodológico da pesquisa, proveu as Secretarias Estaduais de Educação com equipamentos necessários à entrada e processamento de dados e treinou seus quadros técnicos para a realização dos levantamentos previstos. Ao final desse projeto, foi elaborado um novo projeto: BRA/92/002 - Sistema Nacional de Avaliação da Educação Básica, com duração até 2001. Foram realizadas duas pesquisas nacionais de avaliação, em 1993 e 1995, com alterações metodológicas, inclusão de novas variáveis, expansão da pesquisa para o ensino privado e ensino médio. Para o aperfeiçoamento do sistema de avaliação houve troca de conhecimentos e experiências com outros países, pela cooperação técnica internacional do PNUD que permitiu acesso a tecnologias de avaliação utilizadas em outros países e o treinamento de técnicos da área, no país e no exterior (BRASIL, 1997).
} 
Livro Didático - PNLD, e o Fundo de Fortalecimento da Escola - Fundescola ${ }^{6}$, neste especialmente com o projeto Plano de Desenvolvimento da Escola - PDE.

Na perspectiva de alterar a seletividade expressa pela distorção idade-série, pelas altas taxas de repetância e de evasão, novas regulamentações propiciaram a criação, pelos sistemas de ensino e escolas, de mecanismos flexibilizadores da avaliação da aprendizagem, especialmente importantes na regulação do fluxo escolar, a exemplo da classificação/reclassificação, progressão continuada e progressão parcial. Esses mecanismos apareceram associados à flexibilização da organização da educação básica (ciclos ${ }^{7}$, alternância de períodos de estudos, grupos não seriados e outros), à possibilidade de aceleração de estudos para alunos com atraso escolar e à obrigatoriedade de estudos de recuperação, preferentemente paralelos ao período letivo.

Segundo Locatelli (2002, p. 5) coube à avaliação sistêmica da educação básica, o objetivo de "monitorar a qualidade" e de promover a incorporação da avaliação externa no cotidiano escolar como apoio para melhorar a qualidade do ensino. $\bigcirc$ conceito de monitorar, formulado pela Cepal (1995) relaciona-se com a gestão administrativa e consiste no exame contínuo ou periódico da operacionalização do previsto, visando a controlar o cumprimento do que foi estabelecido como metas em projetos sociais.

O texto da Lei n. 9.394 (BRASIL, 1996), de 20 de dezembro de 1996, expressa esse objetivo e a forma de atendê-lo. $\bigcirc$ Art. 9 dessa Lei estabelece que a obtenção, análise e disseminação de informações sobre a educação e o processo nacional de avaliação do rendimento escolar no ensino fundamental, médio e superior, em colaboração com os sistemas de ensino, objetivando a definição de prioridades e a meIhoria da qualidade do ensino; são incumbências da União "em colaboração com os sistemas de ensino". Além disso, essa Lei estabeleceu, no seu art. 87 ( $\left(3^{\circ}\right.$, inciso IV), como dever dos municípios e, supletivamente, dos estados e da União, a integração de todos os estabelecimentos de ensino fundamental ao sistema nacional de avaliação do rendimento escolar até o final da Década da Educação (1997- 2007).

Aprimorando o processo de monitoramento da qualidade, em 1997, o Saeb introduziu as "Matrizes de Referência", pela opção teórica, de natureza cognitivista, para a construção dos descritores como base para a construção dos itens de prova que serão utilizados para avaliar o desempenho do aluno nas diferentes disciplinas. A elaboração dessas Matrizes iniciou-se com uma ampla consulta nacional sobre os conteúdos praticados nas escolas brasileiras de ensino fundamental e médio, tendo a definição apresentada em documento do Saeb (PERRENOUD, 1993 apud BRASIL, 2002, p. 11)

\footnotetext{
${ }^{6}$ A presença e a atuação dos gestores do Banco Mundial foi decisiva no Fundescola implementado por intermédio do Plano de Desenvolvimento da Escola -PDE- e induziu o governo brasileiro a criar, em 1996, o Fundo de Manutenção e Desenvolvimento do Ensino Fundamental e de Valorização do Magistério (FUNDEF), instrumento institucional para redistribuir recursos financeiros e concentrá-los no ensino fundamental.

${ }^{7}$ As mudanças na organização da educação básica nos anos 90 estão relacionadas às estratégias recomendadas pelo Banco Mundial que, segundo Torres (2003), são de uma lógica de análise econômica baseada só na relação custobenefício e na taxa de retorno, na fixação de variáveis observáveis, quantificáveis, que não envolvem aspectos qualitativos, que deveriam ser a essência da educação.
} 
Nesse novo modelo, buscou-se a associação dos conteúdos às competências cognitivas utilizadas no processo da construção do conhecimento. Competência, segundo Phillipe Perrenoud (1993), é a 'capacidade de agir eficazmente em um determinado tipo de situação, apoiando-se em conhecimentos, mas sem se limitar a eles'. Para enfrentar uma situação, geralmente, colocam-se em ação vários recursos cognitivos complementares, entre os quais os conhecimentos. 'Quase toda ação mobiliza alguns conhecimentos, algumas vezes elementares e esparsos, outras vezes complexos e organizados em rede'.

A abordagem das competências que é assumida no Saeb também se encontra presente na ação da administração federal a partir de dispositivos legais, mais especificamente do disposto no art. 9०, inc. IV da LDBEN/96 (BRASIL, 1996), na elaboração dos Parâmetros Curriculares Nacionais - PCNs e das Diretrizes Curriculares do Ensino Fundamental e do Ensino Médio ${ }^{8}$. Há nesses documentos uma determinada concepção de avaliação, do ensino, da aprendizagem e da escola.

A relação entre diretrizes curriculares e avaliação com vistas à eficiência e eqüidade é enfatizada no parecer que aprova as diretrizes curriculares nacionais para o ensino médio, tendo como relatora Guiomar Namo de Mello (CONSELHO NACIONAL DE EDUCAÇÃO, 1998b), que recomenda:

[...] "responsabilização", avaliação de processos e de resultados, participação dos interessados, divulgação de informações, que imprimam transparência às ações dos gestores, diretores, professores, para que a sociedade em geral e os alunos e suas famílias em particular, participem e acompanhem as decisões sobre objetivos, prioridades e uso dos recursos.

Considerando a avaliação como condição necessária da autonomia, o parecer segue requerendo "qualificação permanente dos que trabalham na escola, em especial dos professores" e a instituição de "[...] mecanismos de prestação de contas que facilitem a responsabilização dos envolvidos". Clarifica ainda as razões para essa política de avaliação: "[...]Para a identidade e a diversidade, a informação é indispensável na garantia da igualdade de resultados. Para a autonomia ela é condição de transparência da gestão educacional e clareza da responsabilidade pelos resultados" (BRASIL, 1998b).

Em relação às iniciativas federais do período de 1995 a 2002, encontra-se em discurso oficial o reconhecimento de que

[...]com a atual reforma, sai de cena o Estado-executor, assumindo seu lugar o 'Estado- regulador' e o 'Estado-avaliador'. Essa mudança de paradigma exige uma verdadeira reengenha-

${ }^{8}$ Ver Bonamino e Martínez (2002).

Ensaio: aval. pol. públ. Educ., Rio de Janeiro, v. 16, n. 59, p. 229-258, abr./jun. 2008 
ria do setor público. Trata-se da difícil tarefa de substituir controles burocráticos por uma nova cultura gerencial, que incorpora a política de avaliação como elemento estratégico da gestão pública (CASTRO, 1998, p. 9).

Por outro lado, Frigotto e Ciavatta (2003) criticam a adoção do "pensamento pedagógico empresarial e as diretrizes dos organismos e das agências internacionais e regionais, dominantemente a serviço desse pensamento como diretriz e concepção educacional do Estado

Trata-se de uma perspectiva pedagógica individualista, dualista e fragmentária coerente com o ideário da desregulamentação, flexibilização e privatização e com o desmonte dos direitos sociais ordenados por uma perspectiva de compromisso social coletivo. Não é casual que a ideologia das competências e da empregabilidade esteja no centro dos parâmetros e das diretrizes educacionais e dos mecanismos de avaliação (FRIGOTTO; CIAVATTA, 2003, p. 93-130).

Mas, como se dá a construção científica na análise das informações geradas pelo Saeb e quais são as tendências e focos no período de sua consolidação? Como se configura o campo de pesquisa da avaliação objetivando a definição de prioridades e a melhoria da qualidade do ensino?

Estudo realizado sobre a produção acadêmica acerca da avaliação na educação básica no Brasil, publicada em dez periódicos nacionais entre 1990 a 1998 (BARRETTO; PINTO, 2001, p. 1), encontrou, entre os mais de 200 textos localizados, "a presença majoritária de artigos que versam sobre idéias, conceitos, pressupostos, tendências da avaliação". Da análise emergem dois modelos que permeiam o discurso sobre a avaliação naquele período.

Um dos discursos, reporta-se essencialmente à avaliação qualitativa do ensino, valoriza o processo de aprendizagem, concentrase na avaliação feita no interior da própria escola pelos atores educacionais. $\bigcirc$ outro, volta-se para a avaliação dos resultados, valoriza o produto da aprendizagem, utiliza largamente recursos quantitativos e alta tecnologia e recorre à avaliação externa da escola (BARRETTO, 2000).

Com maior número de trabalhos identificados por Barretto e Pinto (2001), define-se o modelo "que, a partir de diferentes vertentes teóricas, faz a crítica ao paradigma positivista e se dedica às questões do estatuto científico da avaliação da qualidade do ensino com ênfase nas variáveis do processo, mais do que no produto da avaliação" propondo que "a sua natureza deve ser eminentemente dialógica e dialética, voltada para a transformação, tanto no plano pessoal como no social" (BARRETTO, 2000, p. 5). Nesse modelo, o eixo da avaliação desloca-se de uma preocupação técnica de medir o rendimento do aluno " e passa a centrar as atenções em torno das condições em que é oferecido o 
ensino, da formação do professor e de suas condições de trabalho, do currículo, da cultura e da organização da escola e da postura de seus dirigentes e demais agentes educacionais". Ainda, como assinala a autora, "essa mudança de enfoque, que explora sobretudo as relações intermediárias entre as análises macroestruturais e as abordagens micro, vem possibilitando a paulatina superação da tradição crítico-reprodutivista".

Nessa vertente, destacam-se os trabalhos de Franco (1990, 1994) argumentando que a unidade de análise da avaliação educacional deve ser o vínculo indivíduo sociedade numa dimensão histórica e que se considere a complexidade do conceito de qualidade do ensino, como um produto histórico e social. A avaliação do tipo emancipatório dentro de um paradigma dialético constitui proposta desenvolvida por Pedro Demo (1990) e também está relacionada a um paradigma alternativo que Ana Maria Saul (1992) propõe como avaliação emancipatória e que se realiza a partir de três eixos: avaliação democrática, crítica institucional e construção coletiva. A avaliação nas escolas constitui objeto de estudos de Luckesi (1991, 1992, 1996), de André $(1990,1996)$ e de Ludke (1995) abordando mudanças necessárias nas concepções da avaliação no processo de ensino- aprendizagem e nas relações de poder nas mediações presentes no ato de avaliar.

○ "núcleo duro da avaliação da aprendizagem", expressão de Barretto (2000), é o outro modelo de discurso na produção científica brasileira dos anos 90 . É o "modelo de avaliação em larga escala", "ancorado no paradigma positivista" com "papel estruturante das reformas educacionais em curso no país". Essa nova abordagem da avaliação também significa uma nova lógica nas políticas públicas, sendo implementadas em educação.

Os escritos que introduzem modelos e metodologias de avaliação em larga escala nos meios educacionais brasileiros, têm a preocupação de, por meio deles, delinear o perfil cognitivo da população, permitindo reconstituir detalhes da trajetória escolar de populações que freqüentam a escola e identificar a transição de um estágio cognitivo dos sujeitos para outro. Podem ser utilizados também para estabelecer relações entre o perfil cognitivo e cultural de segmentos da população com os novos modelos de organização da produção, bem como com os novos pleitos de participação nas sociedades contemporâneas (BARRETTO, 2000).

Constituem marcos da nova abordagem da avaliação os trabalhos de Ribeiro (1991), Fletcher e Castro (1993) e Klein e Ribeiro (1991, 1995) que, utilizando informações educacionais presentes nos censos demográficos, demonstraram ser a repetência, e, sobretudo a repetência nas séries iniciais do ensino fundamental, o grande problema do sistema educacional brasileiro, e que estimularam as políticas de progressão continuada e de aceleração escolar. Numa linha de continuidade, encontram-se além dos relatórios divulgados pelo INEP, alguns estudos realizados com base no Saeb, com destaque para os que incluem as características escolares nos

\footnotetext{
9 BARRETO, 2000, p. 5.
} 
modelos analíticos de "eficácia" e de "eqüidade escolar" compreendendo, respectivamente, características escolares associadas ao desempenho médio das escolas e que diminuem o impacto do nível socioeconômico dos alunos no desempenho na mesma escola. Há aínda uma perspectiva de análise mais ampla da política de avaliação educacional no Brasil que se encontra presente em estudos como os desenvolvidos por Franco (2001), Sousa (1997), Bonamino (2002) e Vianna (2003).

Apesar de o Saeb ter sido implantado em 1990, os estudos que analisam a sua base de dados são localizados a partir do final dessa década, salientando-se os trabalhos de Fletcher (1993), de César e Soares (2001), de Barbosa e Fernandes (2001), Franco (2001), Soares e outros (2001, 2002), Soares (2004) e Franco e outros (2005, 2007). Se no primeiro momento, a construção científica com base nos resultados do Saeb focaliza as características dos alunos, logo o foco é deslocado para os fatores e práticas das escolas ${ }^{10}$. Constata-se que vários trabalhos internacionais na linha da "efetividade da escola" são referenciados nos documentos do Saeb (INEP, 2002) e que essa abordagem, a da "escola eficaz", também é identificada em estudos realizados a partir da base de dados desse sistema (FLETCHER; CASTRO, 1993; BARBOSA; FERNANDES, 2001; SOARES et.al., 2002; FRANCO et al., 2005, 2007). Como esclarece Sammons (2006), a partir de 1995, a pesquisa sobre "efetividade escolar" foi intensificada por estar no campo de interesse da política governamental no Reino Unido, nos Estados Unidos e em outros países com vistas a elevar padrões educacionais.

Revendo pesquisas realizadas ao longo de mais de trinta anos, Sammons (2006) conclui que a "efetividade escolar" é necessária mas não é condição suficiente para qualquer definição aceitável de uma "boa escola". É vista como um conceito relativo, que é tanto resultado como dependente do tempo. Não busca medir o impacto de escolarização como um todo, ao invés, examina diferenças no impacto de uma instituição em comparação com outra, levando em conta a entrada (características iniciais dos estudantes). Para obter uma clara imagem da efetividade é preciso colocar um foco sobre os resultados sociais e afetivos além dos cognitivos geralmente considerados. Reconhece-se que pode haver variação interna em efetividade no departamento ou no nível de classe, e que efeitos de professor tendem a ser substancialmente maiores do que as diferenças das escolas. Os efeitos da escola são geralmente maiores para estudantes de minorias étnicas ou de desvantagens econômicas.

Elucidar os efeitos das fatores escolares e, em particular, o efeito das práticas docentes de sala de aula, no desempenho do estudante, tem sido difícil em razão da metodologia do Saeb. Embora haja condições para correlacionar a medida de resultado com as características socioeconômicas dos alunos e com as características da escola, encontra-se uma limitação importante pois a única medida de resultado se atém ao objetivo cognitivo e a habilidade dos alunos é medida apenas uma vez (SOARES et al., 2002). Além disso, as dimensões de qualidade da escola e do ensino são caracterizadas por meio de respostas de professores e diretores de escola aos "questionários contextuais". Portanto, processos internos da escola e de salas de aula

\footnotetext{
${ }^{10}$ A expressão "efeito de escola" vem sendo utilizada para designar a influência ou contribuição que fatores escolares exercem sobre o desempenho acadêmico dos alunos do ensino fundamental e médio em estudos que consideram aqueles fatores em comparação com outros fatores individuais, as características pessoais e familiares dos estudantes.
} 
não são satisfatoriamente captados através de questionários, a forma de coleta dos dados do Saeb. Como mostra o estudo de Wenglinsky (2002), para analisar o que faz com que algumas escolas sejam eficazes, e, sobretudo, para estudar as práticas de sala de aula do professor, é necessário basear-se principalmente em resultados de abordagem qualitativa e superar os limites da metodologia estatística.

\section{A "boa escola" ou a "escola eficaz" e as evidências do Saeb no discurso da avaliação}

A partir de 1995, o Brasil conseguiu implantar um sistema de avaliação e informação da educação por meio da reestruturação do Inep e com a realização de censos variados e testes de desempenho em todos os níveis de ensino. Segundo Paulo Renato Souza, que foi ministro da Educação no governo Fernando Henrique Cardoso, o país "criou uma cultura de avaliação, absorvida pela sociedade e referência para os gestores e analistas da educação brasileira" (SOUZA, 2006, p. 3).

Com a posse do novo governo federal, eleito em 2002, a discussão acerca do sistema de avaliação e informação da educação se intensificou. Embora a organização do Saeb não tenha sido modificada, uma grande polêmica ocorreu em torno dos resultados divulgados a partir dos testes aplicados em 2001 e de sua comparação na série histórica a partir de 1995.

Os dados do Saeb analisados em cada um dos anos, em que se realizou o exame desde 1995 até 2003, mostram a insuficiência (médias obtidas abaixo da média mínima satisfatória) nos índices de desempenho dos alunos quanto às habilidades e competências esperadas para cada nível de ensino (INEP, 2004). Considerando a distribuição dos alunos pelos quatro estágios de construção de competências para sua série nos testes do Saeb, constata-se que maior insuficiência está na $4^{a}$ série. Em Língua Portuguesa há apenas $5 \%$ dos alunos no estágio adequado e, um problema ainda maior, pois $22 \%$ dos alunos estão no estágio muito crítico, ou seja, apresentaram resultados insatisfatórios em relação ao nível esperado. Em Matemática, há apenas $6,8 \%$ dos alunos no estágio adequado e 12,5\% no estágio muito crítico. $\mathrm{Na} 8^{a}$ série, a situação parece melhor em Língua Portuguesa com 10,3\% dos alunos com desempenho no estágio adequado e 4,9\% no estágio muito crítico, com resultados insatisfatórios.Em Matemática é menor e de apenas $3 \%$ o percentual de alunos com desempenho adequado, observando-se $7 \%$ do grupo com resultados insatisfatórios. $\mathrm{Na} 3^{a}$ série do Ensino Médio, os percentuais de alunos no estágio adequado (5\%) e no estágio muito crítico (6\%) são similares em Língua Portuguesa e Matemática.

Por outro lado, uma tendência ao decréscimo revelando a ausência de melhorias ao longo do período, é o que se manifesta claramente na série histórica dos indicadores de desempenho dos alunos nos exames do Saeb, tomados a cada dois anos entre 1995 e 2003. Em Língua Portuguesa, a média de desempenho decresce respectivamente, de 188,3 para 169,4 na $4^{a}$ série; de 256,1 para 232,0 na $8^{a}$ série e de 298,0 para 262,3 na 3a série do Ensino Médio. Em Matemática há decréscimos na média de desempenho de 190,6 para 171,1 na $4^{a}$ série, de 253,2 para 245,0 na $8^{a}$ série e de 281,9 para 278,7 na 3ª série do Ensino Médio (INEP, 2004). 
Esses valores, tão negativos ao longo de quase dez anos, suscitam não apenas a insatisfação e crítica quanto às políticas educacionais e à demanda de ações mais efetivas para a melhoria da qualidade do ensino nas escolas, mas também explicações que salientam como fator a expansão do acesso à escolarização básica em detrimento da qualidade do ensino.

É unânime o reconhecimento dos avanços de nosso país na inclusão de crianças e jovens na escola no período 1995-2002. Nesse curto período de tempo fomos capazes de universalizar o acesso à educação para as crianças de 7 a 14 anos, saltando de $87 \%$ para $97 \%$ a escolarização dessa faixa etária em apenas sete anos. A inclusão deu-se especialmente entre os mais pobres e as crianças das regiões mais carentes. De outro lado, as taxas de repetência e evasão escolar se reduziram, melhorando a distorção idade/série. Como conseqüência, mais estudantes estão concluindo o Ensino Fundamental e o Ensino Médio. A experiência internacional ensina que em períodos de forte incorporação de novos segmentos populacionais à escola deve-se esperar uma queda apreciável nos índices de desempenho dos alunos do conjunto do sistema educacional. Isso não significa que o sistema tenha piorado em termos de qualidade com o ingresso de alunos provenientes de famílias mais humildes e menos instruídas. Desde logo, os novos integrantes do sistema estão muito melhor do que estavam antes de ingressarem na escola, pois estão aprendendo. Seu desempenho inicial, porém, é inferior em relação aos demais alunos que já estavam na escola e que provêm de famílias mais educadas. Como conseqüência, a média do novo conjunto de estudantes é menor do que a existente antes da incorporação maciça dos novos alunos. Esse efeito precisa ser compensado com melhorias nos demais fatores que influenciam o desempenho dos alunos vinculados ao funcionamento da escola, como a qualificação de professores, a qualidade do material didático ou os métodos de ensino (SOUZA, 2006, p. 3).

Em relação às políticas orientadas para recursos escolares que, nos últimos vinte anos, não têm estado associadas à melhoria discernível no desempenho dos estudantes, em países desenvolvidos e em desenvolvimento, Hanushek (2002) propõe incentivos financeiros às escolas e a seus profissionais visando a aperfeiçoar o uso desses recursos. Dentre as políticas de incentivos da escola, o autor se refere ao pagamento direto por relações de desempenho, na forma de remuneração por mérito aos professores e de oferta de prêmios para toda a escola, envolvendo também os estudantes. A pesquisa de Wenglinsky (2002) reforça tais políticas ao evidenciar que as práticas de sala de aula têm realmente um efeito importante sobre o desempenho dos estudantes e que, em conjunto com outros aspectos do ensino, este efeito é, pelo menos, tão forte quanto o do background do estudante. Segundo os resultados dessa pesquisa, um desenvolvimento profissional específico parece influenciar fortemente as práticas docentes: quanto mais capacitação os professores recebem em aprendiza- 
gem pela prática e sobre o conteúdo, mais provavelmente eles se engajarão em promover ensino-aprendizagem ativo, que estimula estudantes a crescer independentemente de seus backgrounds. Para Wenglinsky (2002), são esses professores que podem realmente promover o alcance de melhores resultados escolares, fazendo das escolas em que atuam, instituições de sucesso escolar.

Na mesma direção dos estudos de Hanushek (2002) e de Wenglinsky (2002), converge a orientação de Slavin (2003) para políticas educacionais na América Latina e Caribe, no âmbito do programa internacional PREAL - Partnership for Educational Revitalization in the America's. $O$ discurso do PREAL preconiza que "a chave para o aprimoramento escolar na América Latina será o desenvolvimento profissional com enfoque na mudança integral da escola, incluindo a adoção de métodos e materiais já provados, por toda a escola" e que "a mudança escola-por escola" deve-se expandir para o sistema "com apoio de todos os níveis da administração escolar". Os requisitos para "uma reforma eficaz em educação" dependem de quatro fatores nas salas de aulas: qualidade da instrução; níveis de instrução adequados às necessidades dos alunos; incentivos para os alunos e tempo apropriado para o aprendizado (SLAVIN, 2003).

No Brasil, a "boa escola" é o componente principal do discurso da avaliação considerando as evidências do Saeb acerca dos fatores associados ao aprendizado como sinalizadores da relação entre a adoção de boas práticas e o sucesso escolar (PACHECO; ARAUJO, 2004; KLEIN, 2005). Esses fatores distribuem-se em dois eixos centrais: o das condições de vida dos alunos, de suas famílias e de seu contexto social, cultural e econômico e o da própria escola, descrito por meio dos professores, diretores, projeto pedagógico, insumos, instalações, estrutura institucional, "clima" da escola e relações intersubjetivas no cotidiano escolar. Essa distinção justifica a diferenciação entre políticas sociais e as específicamente educacionais.

Aquilo que se refere à escola situa-se dentro das possibilidades de intervenção dos gestores de políticas públicas educacionais. Nesse sentido, a escola passa a ser uma instituição fundamental para promover a eqüidade, bem como proporcionar o desenvolvimento dos saberes básicos, contribuindo para a inclusão social e econômica do cidadão, independente da sua origem social. Portanto, uma boa escola é aquela que permite o aprendizado, com qualidade e para todos. Os fatores extra-escolares dependem de macropolíticas que interfiram nas condições das famílias e no combate à exclusão social, estariam stricto sensu fora do âmbito de uma política educacional, muito embora possa haver políticas de combate à pobreza associadas à Educação (PACHECO; ARAUJO, 2004).

Na perspectiva de que desenvolver a "boa escola" situa-se no campo de intervenção dos gestores de políticas públicas educacionais, o Sistema de Avaliação da Educação Básica - Saeb é ampliado a partir de 2005, acrescentando-se a Avaliação Nacional do Rendimento Escolar - Anresc, divulgada como Prova Brasil, de caráter universal do desempenho em Matemática e em Língua Portuguesa (leitura) de alunos de $4^{a}$ e $8^{a}$ séries do ensino fundamental em cada unidade escolar pública. Continua 
a ser realizado exame bienal de proficiência, aplicado em redes públicas e privadas brasileiras e recebe o nome do Saeb, no sentido da continuidade da série histórica iniciada em 1999.

\begin{abstract}
A Prova Brasil foi idealizada para produzir informações sobre o ensino oferecido por município e escola, individualmente, com o objetivo de auxiliar os governantes nas decisões e no direcionamento de recursos técnicos e financeiros, assim como a comunidade escolar no estabelecimento de metas e implantação de ações pedagógicas e administrativas, visando à melhoria da qualidade do ensino (INEP, [2007?]).
\end{abstract}

Em fevereiro de 2007 pelo INEP foram divulgados os "resultados desagregados" por rede, em cada região, unidade da Federação, município e escola, da primeira edição da Prova Brasil e do Saeb, ambos aplicados em novembro de 2005. Tais resultados revelaram os piores índices de rendimento entre os alunos da $8^{a}$ série do ensino fundamental e da $3^{a}$ série do ensino médio desde 1995. $O$ desempenho dos alunos da quarta série do ensino fundamental em 2005 melhorou três pontos em relação aos resultados do Saeb aplicado em 2003, mas ainda é inferior ao de dez anos atrás.

Numa perspectiva de mercado ${ }^{11}$, os resultados foram tabulados e utilizados pela mídia para comparação por rankeamento de municípios e até de escolas (VEJA o ranking..., 2007). Dois meses depois, novo rankeamento de municípios foi feito e divulgado pela mídia (GOIS; TAKAHASHI; SELIGMAN, 2007), então com base no Ideb.

novo índice, o ldeb, é um indicador de qualidade educacional, desenvolvido pelo INEP, que combina informações de desempenho obtido pelos estudantes ao final das etapas de ensino $\left(4^{a}\right.$ e $8^{a}$ séries do ensino fundamental e $3^{a}$ série do ensino médio, em exames padronizados (Prova Brasil ou Saeb), com informações sobre rendimento escolar (taxas de aprovação). O Ideb tem dois objetivos: "a) detectar escolas e/ou redes de ensino cujos alunos apresentem baixa performance em termos de rendimento e proficiência; b) monitorar a evolução temporal do desempenho dos alunos dessas escolas e/ou redes de ensino" (INEP, 2007, p. 1).

Pela análise oficial, apenas 160 de 55 mil unidades escolares públicas do país, têm Índice de Desenvolvimento da Educação Básica igual ou maior que 6 numa escala de 0 a10, com uma nota equivalente à média dos países desenvolvidos da OCDE. Em termos de país, nas séries iniciais do ensino fundamental, o ldeb é de 3,8, com a meta governamental de atingir 6 até 2022.

\footnotetext{
${ }^{11}$ Em análise de artigos sobre "avaliação de monitoramento", Duran $(2003$, p. 6) já havia assinalado que "O que não é explicitado [...] e que, de fato, parece guiar a política educacional voltada para a educação básica é a progressiva implantação do modelo mercadológico, com a aplicação de testes para os alunos, com a publicação dos resultados do rendimento por escola, para efeito de orientação dos "consumidores" da mercadoria educacional".
} 
A análise das evidências do Saeb, agora a partir dos resultados da Prova Brasil continua sendo norteado pelos fatores da "boa escola". Nessa direção, o estudo "Aprova Brasil, o direito de aprender", realizado pelo Unicef, identificou fatores comuns a 33 escolas do País que, apesar de todas as condições desfavoráveis, conseguiram causar um forte impacto positivo sobre a vida e a aprendizagem dos alunos. Tais escolas foram selecionadas com base nos Indicadores de Efeito Escola - IEE, sendo considerados dados socioeconômicos dos alunos, perfil do município onde está a escola e o desempenho médio na Prova Brasil 2005. A ação da escola como agente de transformação da realidade dos alunos foi avaliada em sete dimensões consideradas fundamentais para a aprendizagem: 1) ambiente educativo - respeito, solidariedade e disciplina na escola; 2) prática pedagógica - proposta pedagógica da escola, planejamento, autonomia dos professores e trabalho em grupo de professores e alunos; 3) avaliação - além das provas e das formas tradicionais de avaliação, processos de auto-avaliação, por participação dos alunos em projetos especiais, etc; 4) gestão escolar democrática - compartilhamento de decisões e informações com professores, funcionários, pais e alunos e participação dos conselhos escolares; 5) formação e condições de trabalho dos profissionais da escola - habilitação dos professores, formação continuada e estabilidade da equipe escolar; 6) ambiente físico escolar - materiais didáticos, instalações, existência de bibliotecas e espaços de prática de esportes, condições da sala de aula; e 7) acesso, sucesso e permanência na escola - índices de falta, abandono e evasão escolar, defasagem idade-série.

Em que as conclusões do estudo "Aprova Brasil" contribui para a descrição dos fatores da "boa escola"? $\bigcirc$ êxito dos estudantes é atribuído ao professor em 32 das 33 escolas analisadas, em que os aspectos mais destacados foram: o empenho, a competência, a capacitação, o interesse, a dedicação e a abertura para criar, inventar atividades e estimular os alunos. Relata-se o compromisso dos professores em relação à escola, aos alunos e à comunidade, que se concretiza na forma de relacionamento, na busca por capacitação, na disponibilidade ao diálogo. $\bigcirc$ fato de serem exigentes e cobrarem responsabilidade dos alunos foi destacado fortemente pelos alunos e pais. Outro aspecto destacado é a atitude do professor em relação ao processo da aprendizagem, como a paciência, a calma, a forma divertida de ensinar, a capacidade de dialogar e a disposição de manter a disciplina na base de regras acordadas entre todos. Foram identificados também aspectos afetivos da relação entre professores e alunos, destacando o carinho, a dedicação, a amizade e o cuidado para com as necessidades de cada um. É importante assinalar que, na maioria das escolas, os professores têm nível superior completo e há muitas referências feitas aos processos de capacitação docente: participação em cursos, formação continuada, busca de especialização e a própria escola desenvolvendo atividades de capacitação.

O estudo "Aprova Brasil" evidencia que os alunos foram reconhecidos como os principais responsáveis pelo bom êxito na prova em 25 das 33 escolas. Expressões como 'a qualidade dos alunos', 'alunos interessados em aprender', 'maturidade dos alunos e compromisso em aprender', 'porque os alunos são exigentes', 'o próprio esforço dos alunos', 'crença no potencial das crianças', 'os alunos são 
inteligentes', 'a capacidade dos alunos', 'o empenho e a dedicação dos alunos' são exemplos de uma visão majoritariamente positiva em relação às crianças. Relaciona-se ao envolvimento dos alunos nas atividades de ensino, o fato de o bom desempenho na "Prova Brasil", em 21 escolas, estar relacionado à proposta pedagógica, que inclui o desenvolvimento de projetos especiais tais como "aulas de artes que ensinam conceitos de geometria", projetos de estímulo à leitura, "incentivo ao jogo de xadrez para ajudar no raciocínio matemático, horta comunitária, jornal mural e rádio na escola.

Em síntese, os componentes de "boa escola" identificados pelo estudo "Aprova Brasil" são: boas práticas pedagógicas, professores comprometidos e qualificados, participação ativa dos alunos, gestão democrática e parcerias externas. Isso fundamenta um deslocamento de foco das escolas em direção às práticas de salas de aula e ao desempenho dos professores.

Estudo recentemente divulgado por Franco e outros (2007) com base nos resultados em Matemática da $4^{a}$ série do Ensino Fundamental pelo Saeb de 2001, confirma resultados de outras investigações brasileiras sobre o "efeito escola". $\bigcirc$ artigo apresenta uma abordagem que, segundo os autores, "permite avaliar adequadamente o efeito das políticas e práticas que aumentam a qualidade da educação, a despeito de, eventualmente, aumentar a desigualdade na distribuição da aprendizagem escolar". Os resultados dessa abordagem, embora delimitados pelas variáveis incluídas no questionário contextual do Saeb, assinalam a importância das práticas docentes, pois enfatizam que

a escola faz diferença em especial por meio do "clima acadêmico" [...] captado via variáveis que enfatizaram a ênfase em passar e corrigir dever de casa, a organização de um cantinho de livros dentro da sala de aula e a manutenção de um bom clima disciplinar, da liderança do diretor, que induzia a colaboração entre professores, e da disponibilidade de recursos da escola, captado via variáveis que mensuravam tanto a disponibilidade e conservação de equipamentos quanto a existência de pessoal e de recursos financeiros na escola. (FRANCO et. al., 2007, p. 294).

Também no campo da pesquisa internacional, o estágio atual, exemplificado pelo estudo de Hanushek e outros (2005), volta-se mais para o interior da escola, para a atividade propriamente dita de ensinar e aprender. $\bigcirc$ construto "qualidade de ensino" é retomado como estando associado à qualidade do professor, definida principalmente pelas práticas pedagógicas, como mais relevante que o nível de formação do professor ou a performance deste em exame de certificação. $\bigcirc$ estudo revela que há uma variação substancial na qualidade de ensino, a maior parte da qual dentro das escolas mais do que entre elas. Confirma que bons professores tendem a ser efetivos para obter maior desempenho de estudantes de todos os níveis de habilidade e, embora a qualidade do professor pareça não se relacionar com os graus avançados de formação ou de certificação: é a experiência que importa, principalmente no primeiro ano de trabalho docente. 
"Como está a educação no Brasil? O que fazer?" Esse é o título do texto analítico e propositivo de Ruben Klein (2006) sobre a educação brasileira em termos de atendimento, fluxo escolar e qualidade de ensino e ações que, o autor acredita, terão efeito positivo para baixar taxas de repetência e evasão e universalizar a conclusão do Ensino Médio e, ainda, para assegurar que "mais de 75\% dos alunos de uma série tenham proficiência (habilidade) acima do nível da escala do Saeb, considerado satisfatório para a referida série". Desse trabalho, destacamos algumas "metas menos ambiciosas" definidas pelo autor:

Existência de currículo básico (mínimo) para todas as séries, o que facilita a capacitação de professores, transferência de escola e avaliações externas; [...] a garantia da boa formação inicial dos professores [...] mudança de metodologia: de aula passiva para participativa; trabalho em grupos na sala de aula; ênfase em fazer o aluno pensar em vez de decorar; encorajar o aluno a perguntar; encorajar o aluno a discutir e debater [...] a avaliação da eficácia dos Cursos Normais Superiores [...] melhoria e incentivo ao uso do livro didático. [...] trabalhar atitude e expectativa dos professores, diretores e funcionários das escolas quanto ao sucesso e progresso dos alunos [...] trabalhar a auto-estima dos alunos [...] incentivar o envolvimento dos pais [...] incentivar a valorização do bom aluno pelos pais, sociedade e escola; 13) manter o jovem na escola de 14 a 18 anos. [...] para acabar ou diminuir a falta de professores, especialmente de Matemática, Física e Química no $E M^{12}$, e também, no $E F^{13}$, permitir que qualquer pessoa com formação superior possa ser professor após fazer um exame de habilitação de conteúdo e passar por um treinamento pedagógico nos moldes propostos acima, em serviço; [...] para atrair profissionais capacitados para a carreira de professor, é necessário valorizar o professor, com plano de carreira, que permita ascensão por mérito e melhoria salarial [...] melhoria da gestão escolar. Autonomia para fazer pequenos reparos. Autonomia para escolher professores; [...] garantir pré-escola de boa qualidade; [...] buscar apoio dos pais e da sociedade (KLEIN, 2006, p. 159-160).

Embora possa haver divergências quanto à proposição político-pedagógica de cada uma dessas metas propostas por Ruben Klein, pode-se identificar nelas a presença de fatores da "escola eficaz" ou da "boa escola" ou ainda do "efeito escola" que foram sendo identificados ao longo de mais de vinte anos da avaliação sistêmica da educação básica no Brasil. Uma questão nos desafia. Como esse rápido balanço pode contribuir para um repensar mais da gestão e da política pública considerando que, se avançamos no processo de avaliação, não estamos conseguindo avançar nos resultados do próprio sistema de educação básica?

\footnotetext{
12 EM- Ensino Médio.

${ }^{13} \mathrm{EF}$-Ensino Fundamental.
} 


\section{Para concluir: reflexões sobre a gestão e a política pública a partir do "Estado-avaliador" na educação básica}

Neste estudo demonstramos que a avaliação, a partir dos meados dos anos oitenta, passou a assumir uma nova centralidade como um dos eixos estruturantes das políticas públicas, em geral, e das políticas educacionais. Segundo Broadfoot (2000), os procedimentos de avaliação constituem hoje um dos mais importantes meios de controle da educação. Para Afonso (2001), há um aumento de interferência e controle pelo Estado por meio da avaliação sistêmica que caracteriza a "radicalização" da "figura do Estado intervencionista". As mudanças das dimensões do Estado sinalizam a transição de uma forma de regulação burocrática e fortemente centralizada para uma forma de regulação híbrida que conjuga o controle estatal com estratégias de autonomia e auto-regulação das instituições educativas.

No Brasil, embora a autonomia dos estabelecimentos de ensino básico, discutida desde meados dos anos oitenta, seja mais retórica do que real, ela é uma justificativa para a avaliação e para a responsabilização dos profissionais da escola e, ainda, por efeito simbólico, vincula-se a uma nova representação sobre o papel do Estado, que está cada vez mais distante das funções de bem-estar social e das obrigações que assumira quando era o principal provedor e fornecedor de bens e serviços educativos. Segundo Ball (2005), duas tecnologias políticas genéricas - a privatização e a performatividade, são utilizadas para provocar as mudanças que configuram "o acordo do Pós-Estado de Bem-Estar" ou "Pós-Estado da Providência do século XXI".

Como assinala Afonso (2001, p. 26), a presença do "Estado avaliador" na educação promove um ethos competitivo pelas avaliações externas e pelo predomínio de uma racionalidade instrumental e mercantil que tende a supervalorizar indicadores e resultados acadêmicos quantificáveis e mensuráveis a despeito de contextos e processos educativos específicos. Através da avaliação pode-se dar aumento (neoconservador) do poder de controle central do Estado em torno dos currículos, da gestão das escolas e do trabaIho dos professores. Pode também ocorrer a indução e implementação (neoliberal) de mecanismos de mercado no espaço público estatal e educacional, neste caso, em função das pressões de alguns setores sociais mais competitivos e das próprias famílias.

O novo modo de regulação do "Estado avaliador" transita de uma forma de regulação burocrática e fortemente centralizada para uma forma de regulação híbrida que conjuga o controle estatal com estratégias de autonomia e auto-regulação das instituições educativas. Essa regulação pode ser interpretada pela articulação dos conceitos de Estado-avaliador (NEAVE, 1988, 1998) e de "quase-mercado" (LE GRAND, 1991). Para Afonso (2001), esta articulação, tensa e relativamente contraditória, pode ser mais bem designada de "avaliação estandardizada criterial com publicitação de resultados".

Como afirma Ball (2005), "a combinação das reformas gerencial e performativa atinge profundamente a prática do ensino e a alma do professor- a 'vida na sala de 
aula' e o mundo da imaginação do professor ". Assim compreendemos que essas reformas e o "novo discurso de trabalho da escola e do discurso nacional da competição" do "Estado avaliador" se expressam nos movimentos da avaliação sistêmica da educação básica no Brasil. A gestão educacional funciona de dentro para fora, ou seja, nas atitudes e culturas, em que professores se sentem responsabilizados e, simultaneamente, comprometidos ou pessoalmente envolvidos com a organização. Performatividade e gestão atuam juntas num processo de cumprimento de metas, melhoria do desempenho e maximização do orçamento.

Tomando de empréstimo a expressão de Lawn (2001), estaríamos vivendo um "novo problema de identidade" tendo a sala de aula e a escola como lugar de fabricação, e sendo traduzida em competências a serem desenvolvidas, praticadas e avaliadas visando à qualidade e ao aperfeiçoamento do sistema educativo. Dá-se assim continuidade a um movimento similar que passa do "profissional colonizado" ao do "profissional moderno". O primeiro emergiu na modernização da administração educacional calcada no controle e subordinação dos professores face aos movimentos sociais dos anos 20. O segundo, construído sobre o anterior, emergiu como discurso de responsabilidade profissional, do Estado de Bem-Estar Social pós-guerra e que produziu um "modelo de partenariato, profissionalismo e de devolução democrática" (LAWN, 2001, p. 127). O Estado democrático busca gerir a nova identidade "oficial" do professor que "é continuamente monitorada, apresentada e mantida, nas novas arenas públicas do trabalho na escola básica - a cultura dos novos encontros e da rede"14.

projeto do "Pós Estado de Bem-Estar Social" promove o "novo discurso de trabalho da escola e do discurso nacional da competição", através de seus regulamentos e ações como os sistemas nacionais de avaliação que, no Brasil se expressam no Saeb, Prova Brasil, Enem, Enade, e outros que estão sendo criados.

Como afirma Ball (2005), a política de reforma do setor público mais do que mecanismos para mudanças técnica e estrutural das organizações tem recursos para reformar os profissionais do setor público, como os professores, ao mudar o significado do que é ser professor. Precisamos então de refletir sobre a gestão e as políticas públicas considerando que: a combinação das reformas gerencial e performativa atinge profundamente a prática do ensino e a alma do professor - a 'vida na sala de aula' e o mundo da imaginação do professor (EGAN, 1994) aspectos específicos e díspares da conduta são reformulados e se muda o local de controle da seleção de pedagogias e currículos (BALL, 2005).

Quais são as possibilidades de mudança? Não há dúvida de que a universalização da educação básica com qualidade, eficiência e eqüidade é um processo contraditório. Tendo em vista a cultura gerencial e performativa do Estado, como aponta Ball (2001, p. 119), há, por um lado "o aumento da individualização, que inclui a destruição das solidariedades baseadas numa identidade profissional comum, na filiação sindical e na construção de novas formas de filiação

14 LAWN, 2001, p. 129. 
institucional". Por outro lado, há " a geração de uma 'comunidade' - cultura corporativa - que envolve a reconfiguração das relações entre o compromisso individual e a ação na organização".

Se os diferentes estudos realizados há pouco mais de vinte anos de avaliação sistêmica da educação básica apontam, entre outros fatores, "boas práticas pedagógicas", "professores comprometidos e qualificados" e "gestão democrática" como componentes fundamentais para reverter a trajetória de fracasso de nossas escolas, como tornar isso realidade pela política pública?

Apostamos na hipótese da retomada da construção da identidade pelos profissionais da educação, como cidadãos e como educadores. Essa aposta se faz na direção que Sousa Santos (1999, p. 60) aponta: a saída é "reinventar a democracia". Especificamente, a "redescoberta democrática do trabalho é condição sine qua non da reconstrução da economia como forma de sociabilidade". E isso vale para os profissionais da educação, pois o trabalho reduzido a mero fator de produção não pode sustentar a cidadania. Portanto, um caminho para a mudança da educação escolar está na revalorização da tradição solidarista, de um "sindicalismo de alternativa civilizacional" e de reconstrução de suas políticas a partir de explicitação e confronto de interesses sociais diferentes e, até antagônicos. Estão postas novas questões: Há outra saída, senão a de destruir a individualização? Há outra saída senão a de reconstrução das solidariedades baseadas na construção de uma nova identidade profissional dos profissionais da educação? Há outra saída senão a de fazer um novo movimento de organização e luta por aspirações e reivindicações que historicamente têm marcado os profissionais da educação? 


\section{Referências}

AFONSO, A. J. Reforma do Estado e políticas educacionais: entre a crise do Estado-nação e a emergência da regulação supranacional. Educação e Sociedade, Campinas, n. 75, p. 15-32, ago. 2001.

ANDRÉ, M. E. D. A. A avaliação na escola e da escola. Cadernos de Pesquisa, São Paulo, n. 74, p. 68-70, ago. 1990.

. Avaliação escolar: além da meritocracia e do fracasso. Cadernos de Pesquisa, São Paulo, n. 99, p. 16-20, nov. 1996.

AZEVEDO, J. M. L. O Estado, a política educacional e a regulação do setor educação no Brasil: uma abordagem histórica. In: FERREIRA, N. S. C.; AGUIAR, M. A. S. (Org.). Gestão da educação: impasses, perspectivas e compromissos. São Paulo: Cortez, 2000.

BALL, S. J. Diretrizes políticas globais e relações políticas locais em educação. Currículo sem Fronteiras, [S. I.], v. 1, n. 2, p. 99-116, jul./dez. 2001.

- Performatividade, privatização e o pós-Estado do Bem-Estar. Educação e Sociedade, Campinas, v. 25, n. 89, set./dez. 2004.

- Profissionalismo, gerencialismo e performatividade. Cadernos de Pesquisa, São Paulo, v. 35, n. 126, set./dez. 2005.

BARBOSA, M. E. F.; FERNANDES, C. A escola brasileira faz diferença? Uma investigação dos efeitos da escola na proficiência em Matemática dos alunos da 4a série. In: FRANCO, C. (Org.). Promoção, ciclos e avaliação educacional. Curitiba: ArtMed, 2001.

BARRETTO, E. S. S. A avaliação na educação básica: entre dois modelos. In: REUNIÃO ANUAL DA ANPED, 23., 2000 , Caxambu. Anais... Caxambu: ANPED, 2000.

BARRETTO, E. S. S.; PINTO, R. P. Estado da arte: avaliação na educação básica (1990-1998). Brasília, DF: MEC, INEP, COMPED, 2001.

BICKEL, W. E. Effective schools: knowledge, dissemination, inquiry. Educational Researcher, v. 12, n. 4, p. 3-5, 1983.

BLOOM, B. S. Características humanas e aprendizagem escolar. Porto Alegre: Globo, 1981. 
BONAMINO, A. C. Tempos de avaliação educacional: o SAEB, seus agentes, referências e tendências. Rio de Janeiro: Quartet, 2002.

BONAMINO, A.; MARTíNEZ, S. A. Diretrizes e Parâmetros Curriculares Nacionais para o ensino fundamental: a participação das instâncias políticas do Estado. Educação e Sociedade, Campinas, v. 23, n. 80, p. 371-388, set. 2002.

BRASIL. Constituição (1988). Constituição da República Federativa do Brasil. Brasília, DF: Senado, 1988.

. Lei n. 9.394, de 20 de dezembro de 1996. Estabelece as diretrizes e bases da educação nacional. Diário Oficial [da República Federativa do Brasil], Brasília, DF, 23 dez. 1996.

. Ministério da Educação. Projeto BRA/96/026 - PNUD. Brasília, DF, 1997.

Parecer CNE/CEB n. 4, de 29 de janeiro de 1998. Diretrizes Curriculares Nacionais para o Ensino Fundamental. Diário Oficial [da República Federativa do Brasil], Brasília, DF, 30 dez. 1998a.

. Parecer CNE/CEB n. 15, de $1^{\circ}$ de junho de 1998. Diretrizes Curriculares Nacionais para o Ensino Médio. Diário Oficial [da República Federativa do Brasil], Brasília, DF, 26 jun. 1998b.

BROADFOOT, P. Un noveau mode de régulation dans un système decentralize: I'état évaluateur. Revue Française de Pédagogie, Paris, n. 130, p. 43-55, 2000.

BROOKOVER, W. B. et. al. Elementary school social climate and school achievement. American Educational Research Journal, n. 15, p. 301-318, 1978.

CASTRO, M. H. G. Palestra inaugural. In: SEMINÁRIO INTERNACIONAL DE AVALIAÇÃO EDUCACIONAL, 1997, Rio de Janeiro. Anais... Brasília, DF: MEC, 1998.

CEPAL. Formulación y evaluación de proyectos sociales. Chile: Proposal, 1995.

CEPAL; UNESCO. Educação e conhecimento: eixo da transformação produtiva com equidade. Brasília, DF, 1995.

CESAR, C. C.; SOARES, J. F. Desigualdades acadêmicas induzidas pelo contexto escolar. Belo Horizonte: UFMG, 2001.

COELHO, M. I. M. Avaliação da educação básica. Belo Horizonte: UNA, 2005.

. Educação e poder: a escola efetiva em discussão. In: SEMINÁRIO INTERNACIONAL DE SOCIOLOGIA DA EDUCAÇÃO, 1984, Rio de Janeiro. Trabalhos apresentados... Rio de Janeiro: PUC-Rio, 1984. Mimeografado. 
COLEMAN, J. S. et. al. Equality of educational opportunity. Washington, DC: U.S. Government Printing Office, 1966.

COSTA, S. L. (Des)governo, (in)governabilidade ou (des)governança? Revista de Administração Pública, Rio de Janeiro, v. 31, n. 1, p. 42-74, mar./abr. 1997.

DEMO, P. Qualidade da educação: tentativa de definir conceitos e critérios de avaliação. Estudos em Avaliação Educacional, São Paulo, n. 2, p. 11-26, jul./dez. 1990.

DURAN, M. C. G. Avaliação: reguladora ou emancipatória? Revista Diálogo Educacional, Curitiba, v. 4, n. 8, p. 97-110, jan./abr. 2003.

EDMONDS, R. R. Effective schools the urban poor. Educational Leadership, v. 3, n. 1, p. 15-27, Oct. 1979.

EGAN, K. Tools for enhancing imagination in teaching. In: GRIMMETT, P. P.; NUEFELD, J. (Ed.). Teacher development and the struggle for authenticity. New York: Teachers College Press, 1994.

FLETCHER, P.; CASTRO, C. M. Mitos, estratégias e prioridades para o ensino de primeiro grau. Estudos em Avaliação Educacional, São Paulo, n. 8, p. 39-56, jul./ dez.. 1993.

FORQUIN, J. C. Escola e cultura. Porto Alegre: Artes Médicas, 1993.

FRANCO, C. O SAEB: Sistema de Avaliação da Educação Básica: potencialidades, problemas e desafios. Revista Brasileira de Educação, Rio de Janeiro, n. 17, p. 127-133, maio/jun./jul./ago. 2001 a.

FRANCO, C. (Org.). Promoção, ciclos e avaliação educacional. Curitiba: ArtMed, $2001 \mathrm{~b}$.

FRANCO, C. et. al. A eficácia escolar no Brasil: investigando práticas e políticas escolares moderadoras de desigualdades educacionais. In: SEMINÁRIO INTERNACIONAL DE QUALIDADE NA EDUCAÇÃO, 2005, Rio de Janeiro. Anais... Rio de Janeiro: Fundação Getúlio Vargas, 2005.

. Qualidade e eqüidade em educação: reconsiderando o significado de "fatores intra-escolares". Ensaio: avaliação e políticas públicas em educação, Rio de Janeiro, v. 15, n. 55, p. 277-298, abr./jun. 2007.

FRANCO, M. L. B. Pressupostos epistemológicos da avaliação educacional. Cadernos de Pesquisa, São Paulo, n. 74, p. 63-67, ago. 1990.

. Qualidade de ensino: critérios e avaliação de seus indicadores. Idéias, São Paulo, n. 22, p. 81-87, 1994. 
FREITAS, D. N. T. A avaliação da educação básica no Brasil: dimensão normativa, pedagógica e educativa In: REUNIÃO ANUAL DA ANPED, 28., 2005, Caxambu . Anais... Caxambu, MG: ANPED, 2005.

FRIGOTTO, G.; CIAVATTA, M. Educação básica no Brasil na década de 1990: subordinação ativa e consentida à lógica do mercado. Educação e Sociedade, Campinas, v. 24, n. 82, p. 93-130, abr. 2003.

GOIS, A.; TAKAHASHI, F.; SELIGMAN, F. Ranking escolar aprova só 0,8\% das cidades. Folha Online, São Paulo, 26 abr. 2007. Disponível em:

$<w w w 1 . f o l h a . v o l . c o m . b r / f o l h a / e d u c a c a o / u l t 305 u 19479 . s h t m l$ - $31 \mathrm{k}$->. Acesso em: 13 maio 2008.

HANUSHEK, E. The failure of input-based schooling policies. Stanford, CA: Stanford University, 2002. NBER Working Paper No. 9040.

HANUSHEK E. et al. The market for teacher quality. Stanford, CA: Stanford University, 2005. NBER Working Paper No. 11154.

INEP. Índice de Desenvolvimento da Educação Básica (Ideb). Brasília, DF, 2007. (Série Documental. Texto para Discussão; 26).

. SAEB 2001: novas perspectivas. Brasília, DF, 2002.

. SAEB 2003. Brasília, DF, 2004.

JENCKS, C. et al. Inequality: a reassessment of the effect of family and schooling in America. New York: Basic Books. 1972.

KLEIN, R. A boa escola. O Globo, Rio de Janeiro, p. 7, 31 mar. 2005.

. Como está a educação no Brasil? $\bigcirc$ que fazer? Ensaio: avaliação e políticas públicas em educação, Rio de Janeiro, v.14, n. 51, p. 139-172, abr./jun. 2006.

KLEIN, R.; RIBEIRO, S. C. O censo educacional e o modelo de fluxo: o problema da repetência. Revista Brasileira de Estatística, Rio de Janeiro, v. 52, n. 197/198, p. 5-45, 1991.

A pedagogia da repetência ao longo das décadas. Ensaio: avaliação e políticas públicas em educação, Rio de Janeiro, v. 3, n. 6, p. 55-62, jan./mar. 1995.

LAWN, M. Os professores e a fabricação de identidades. Currículo sem Fronteiras, [S. I.], v. 1, n. 2, p. 117-130, jul./dez. 2001.

LE GRAND, J. Quasi-markets and social policy. Economic Journal, London, v. 101, n. 408, p. 1256-1267, 1991. 
LOCATELLI, I. Construção de instrumentos para a avaliação de larga escala e indicadores de rendimento: o modelo Saeb. Estudos em Avaliação Educacional, São Paulo, n. 25, p. 3-21, jan./dez. 2002.

LUCKESI, C. Avaliação da aprendizagem escolar: apontamentos sobre a pedagogia do exame. Tecnologia Educacional. Rio de Janeiro, v. 20, n. 101, p. 82-6, jul./ago. 1991.

Avaliação educacional: pressupostos conceituais. Tecnologia Educacional, Rio de Janeiro, v. 25, n. 130-131, p. 26-29, maio/ago. 1996.

. Planejamento e avaliação na escola: articulação e necessária

determinação ideológica. Idéias, São Paulo, n. 15, p. 115-125, 1992.

LUDKE, M. O administrador escolar entre o mito da avaliação e os desafios de sua prática. Estudos em Avaliação Educacional, São Paulo, n. 12, p. 51-7, jul./dez. 1995.

MADAUS, G. F. et al. Schools effectiveness: a reassessment of the evidence. New York: Mc Graw Hill, 1980.

MELLO, G. N. Escolas eficazes: um tema revisitado. In: XAVIER, A. C. et al. (Org.). Gestão escolar: desafios e tendências. Brasília: Ipea, 1994, p. 329-369.

MURPHY, J. et al. Academic Press: translating high expectations into school policies and classroom practices. Educational Leadership, Baltimore, v. 40, n. 3, p. 22-26, Dec. 1982.

NEAVE, G. On the cultivation of quality, efficiency and enterprise: an overview of recent trends in higher education in Western Europe, 1986-1988. European Journal of Education, Oxford, v. 23, n. 1/2, p. 7-23, 1988.

. The evaluative state reconsidered. European Journal of Education, Oxford, v. 33, n. 3, p. 265-284, 1998.

NEPP. O sistema de proteção social no Brasil. Campinas: NEPP, UNICAMP, 1991.

PACHECO, E.; ARAÚJO, C. H. Boa escola: evidências do Saeb. Brasília, DF: INEP, 2004.

PERRENOUD, P. Práticas pedagógicas, profissão docente e formação. Lisboa: Dom Quixote, 1993.

RIBEIRO, S. C. A pedagogia da repetência. Estudos em Avaliação Educacional, São Paulo, n. 4, p. 73-86, jul./dez. 1991.

SAMMONS, P. School effectiveness and equity: making connections. In: INTERNATIONAL CONGRESS FOR SCHOOL EFFECTIVENESS AND 
IMPROVEMENT, 2006, Florida. Embracy diversity: new challenges for school improvement in a global learning society. Fort Lauderdale, Florida, 2006.

SAMMONS, P.; HILLMAN, J.; MORTIMORE, P. Key characteristics of effective schools: a review of school effectiveness research. London: Office for Standards in Education [OFSTED], 1998.

SAUL, A. M. Avaliação emancipatória: uma abordagem crítico-transformadora. Tecnologia Educacional, Rio de Janeiro, v. 21, n. 104, p. 24-31, jan. /fev. 1992.

SLAVIN, R. E. Salas de aula eficazes, escolas eficazes: uma base de pesquisa para reforma da Educação na América Latina. Rio de Janeiro: Fundação Getúlio Vargas, 2003. (PREAL; n. 4).

SOARES, J. F. Qualidade e eqüidade na educação básica Brasileira: a evidência do SAEB-2001. Archivos Analíticos de Políticas Educativas, Florida, v. 12, n. 38, Aug. 2004.

SOARES, J. F. et al. Escola eficaz: um estudo de caso em três escolas da rede pública de ensino do Estado de Minas Gerais. Belo Horizonte: UFMG, FAE, GAME: Fundação Ford, 2002.

Fatores explicativos do desempenho em língua portuguesa e matemática: a evidência do SAEB-99. [S. I.: s. n.], 2001. Mimeografado.

SOARES, J. F.; CÉSAR, C. C.; MAMBRINI, J. Determinantes de desempenho dos alunos do ensino básico brasileiro: evidências do Saeb de 1997. In: FRANCO, C. Promoção, ciclos e avaliação educacional. Porto Alegre: ArtMed, 2001.

SOUSA, S. M. Z. L. Avaliação do rendimento escolar como instrumento de gestão educacional. In: OLIVEIRA, D. A. (Org.) . Gestão democrática da educação: desafios contemporâneos. Petrópolis: Vozes, 1997.

SOUSA SANTOS, B. Reinventar a democracia: entre o pré-contratualismo e o póscontratualismo. In: HELLER, A. et al. A crise dos paradigmas em ciências sociais e os desafios para o século XXI. Rio de Janeiro: Contraponto, 1999.

SOUZA, P. R. Avaliação a serviço da qualidade educativa: reescrevendo a educação. Disponível em : <http://www.reescrevendoaeducacao.com.br/2006>. Acesso em: 27 abr. 2007.

TORRES, R. M. Melhorar a qualidade da educação básica? As estratégias do Banco Mundial. In: TOMASI, L. et al. (Org.). O Banco Mundial e as políticas educacionais. 4. ed. São Paulo: Cortez, 2003.

UNICEF . Aprova Brasil: o direito de aprender: boas práticas em escolas públicas avaliadas pela Prova Brasil. Brasília, DF, 2006. 
VEJA o ranking do Prova Brasil em cidades com mais de 100 mil habitantes. Folha Online, São Paulo, 11 fev. 2007. Disponível em: <wwwl.folha.vol.com.br/folha/ educacao/ult305u19362.shtml - 45k ->. Acesso em: 13 maio 2008.

VIANNA, H. M. Avaliações nacionais em larga escala: análises e propostas. São Paulo: FCC, 2003.

WAISELfISZ, J. O Sistema Nacional de Avaliação do Ensino Público de $1^{\circ}$ grau. Estudos em Avaliação Educacional, São Paulo, n. 4, p. 65-72, 1991.

WENGLINSKY, H. How schools matter: the link between teacher classroom practices and student academic performance. Education Policy Analysis Archives, Florida, v. 10, n. 12, Feb. 2002.

Recebido em: 06/12/2007

Aceito para publicação em: 04/02/2008 